\title{
DESENVOLVIMENTO DE MUDAS DE REPOLHO EM DIFERENTES BANDEJAS COM SUPLEMENTAÇÃO ORGÂNICA NO SUBSTRATO COMERCIAL
}

\author{
Mário Euclides Pechara da Costa Jaeggi ${ }^{1}$ \\ Julio Cesar Gradice Saluci² \\ Maxwel Rodrigues Nascimento ${ }^{3}$ \\ Rogério Rangel Rodrigues ${ }^{4}$ \\ Samuel Ferreira da Silva ${ }^{5}$ \\ Diego Rogério Ferraz ${ }^{6}$ \\ Israel Martins Pereira ${ }^{7}$ \\ Rebyson Bissaco Guidinelle ${ }^{8}$ \\ Alex Justino Zacarias $^{9}$ \\ Wallace Luis de Lima ${ }^{10}$
}

Resumo: Objetivou-se com este trabalho avaliar diferentes tipos de bandejas e concentrações de substratos sobre o desenvolvimento de mudas de repolho. O delineamento experimental utilizado foi o inteiramente casualizado em um esquema fatorial $2 \times 5$, sendo dois tipos de bandejas e cinco concentrações de substratos, com cinco repetições. Os tratamentos foram constituídos por duas bandejas de poliestireno (128 e 200 células) e cinco concentrações de substratos (100/0; 75/25; 50/50; 25/75 e 0/100). Ao 31 ${ }^{\circ}$ dia após semeadura foram avaliadas as seguintes variáveis: altura total da planta; altura da parte aérea, massa seca total e massa seca parte aérea. De acordo com os resultados, a bandeja de 128 células proporcionou melhor desenvolvimento e relação a bandeja 200 células. O substrato vermicomposto na concentração de 0/100\% proporcionou melhor desenvolvimento para todas as características avaliadas.

Palavras-chave: Compostagem; Biometria; Resíduo orgânico.

\footnotetext{
${ }^{1}$ Departamento de Produção Vegetal/Universidade Estadual Norte Fluminense, Brasil. E-mail: mariopechara@hotmail.com.

2 Instituto Federal do Espírito Santo, Brasil. E-mail: juliosaluci@gmail.com.

3 Departamento de Produção Vegetal/Universidade Estadual Norte Fluminense, Brasil. E-mail: maxwel.rn88@gmail.com.

${ }^{4}$ Departamento de Engenharia/Universidade Federal de Lavras, Brasil. E-mail: rogeriorr7@hotmail.com.

${ }^{5}$ Departamento de Produção Vegetal/Universidade Federal do Espírito Santo, Brasil. E-mail: samuelfd.silva@yahoo.com.br.

6 Instituto Federal do Espírito Santo, Brasil. E-mail: diegofvalim@hotmail.com.

7 Instituto Federal do Espírito Santo, Brasil. E-mail: israelmartins80@gmail.com.

8 Instituto Federal do Espírito Santo, Brasil. E-mail: rebysonguidinelle@gmail.com.

9 Instituto Federal do Espírito Santo, Brasil. E-mail: alexjustino12@gmail.com.

10 Instituto Federal do Espírito Santo, Brasil. E-mail: wallace@ifes.edu.br
} 